\title{
Municipios: ¿Modernización o privatización?
}

\author{
Por Valeria S. Verdolini*
}

Cada vez es más frecuente encontrar en los distintos municipios de la Provincia de Buenos Aires ejemplos de privatizaciones o concesiones que hacen los fiscos locales de las distintas etapas que conforman la recaudación, delegando de esta manera directamente el ejercicio de funciones esenciales del Estado en materia tributaria.

Especialmente a partir de la reforma constitucional de 1994 (con la consagración que allí se ha logrado del principio de autonomía municipal del artículo 123), y de sus reflejos en las distintas jurisdicciones provinciales, se han arbitrado en los municipios, con independencia de su magnitud poblacional o geográfica, mecanismos tendientes a optimizar su funcionamiento a partir de la aplicación de un peligroso dispositivo recaudatorio consistente en lo que se conoce como privatización o tercerización de las funciones municipales.

De esta forma, los municipios delegan en empresas privadas o estudios de profesionales (generalmente bajo la forma legal de "consultoras") la función pública consistente en determinar la existencia y cuantía de los créditos fiscales cuya retribución, casualmente, consiste en un porcentaje de lo que se recaude.

Esta idea de privatizar el cobro de impuestos no es nueva en la Provincia de Buenos Aires. La experiencia cuenta con numerosos antecedentes: Pilar, Quilmes, Cañuelas, por mencionar algunos municipios que han tercerizado por ejemplo la provisión del equipamiento informático, la capacitación del personal municipal, la digitalización de los planos de obra (que en la mayoría de los municipios hoy existe solo en formato papel), el relevamiento geoespacial para actualizar el catastro y por supuesto las gestiones de cobro.

Claro está que no veríamos con buenos ojos si la AFIP decidiera contratar una empresa a quien se le encomiende la verificación de la exactitud de las declaraciones juradas de bienes personales o del impuesto a las ganancias de los contribuyentes, fijando como mecanismo de retribución de tales servicios un porcentaje sobre lo que se recaude como consecuencia de la revisión de aquellas, extremo que constituye una función pública indelegable que inequívocamente debe ser cumplida por agentes públicos integrantes de la estructura de recursos humanos del Estado, sujetos, por ello, al poder disciplinario del mismo y a las responsabilidades civiles y penales pertinentes.

Por supuesto que los argumentos a favor son bastante convincentes, esgrimiendo la búsqueda de una mejora en la calidad administrativa, que tiene como fundamento 
principal modernizar al municipio dotándolo de tecnología a partir de la incorporación de herramientas técnicas y capacitación del personal.

Sin embargo, estos argumentos no son más que los utilizados en cualquier proceso de privatización de un servicio público que hemos vivido en nuestro país. De esta manera se infra valorizan los recursos (de todo tipo: humanos y técnicos) del Estado para justificar el desembarco del capital privado, más eficiente y más avanzado según sus defensores.

Claro que, desde el punto de vista constitucional, no parece ser ésta una práctica admisible, puesto que las potestades de aplicación, gestión, verificación y posterior recaudación de los gravámenes no son susceptibles de ser transferidas fuera de la órbita estatal, por elementales razones ligadas a su estrecha relación con el principio constitucional de reserva de ley, a la vez que se vacía al Estado del ejercicio de sus funciones vitales e intrínsecas a su existencia.

Los tributos constituyen prestaciones obligatorias en dinero (o en especie) exigidas por el Estado en ejercicio de su poder de imperio y en virtud de ley, que dan lugar a relaciones de derecho público. Esto implica que el tributo debe cobrarse con arreglo al principio de indisponibilidad del crédito fiscal y como tal no puede ser privatizado o tercerizado en un sujeto particular, toda vez que la función de control fiscal y determinación de deuda fue delegada monopólicamente al Poder Ejecutivo -Jefe de Gabinete en el orden nacional- y como tal es una función indelegable (artículo 100 inc. 7 de la Constitución Nacional y 144 inc. 9 de la Constitución de la Provincia de Buenos Aires), la que además es resguardada por el instituto del secreto fiscal.

Así, la privatización o tercerización de las funciones que integran las distintas etapas de la recaudación tributaria encuentra otra limitación mediante el instituto del secreto fiscal, en tanto aborda la protección del dato puesto bajo resguardo de la administración tributaria.

No podemos omitir considerar que la función pública de la recaudación constituye un quehacer estratégico del gobierno. Dicho esto, la privatización de la misma pone en jaque el aparato fiscal cuando colocamos en manos privadas las bases de datos que contienen todo lo relacionado a la identificación de los contribuyentes y la determinación (tanto la realizada por el particular como la efectuada por el fisco) de sus tributos.

Ni hablar de la retribución de un porcentaje a favor del recaudador privado que se opone al destino del tributo, afectando el mandato constitucional de contribuir y la cláusula de formación del tesoro.

Llama la atención la ideología neoliberal que se esconde detrás de estas privatizaciones de áreas propias de la función pública, bajo el pomposo mote de 
"modernización", que no es otra cosa que la mera privatización, es decir, pasar la gestión de la cobranza y apremio a manos privadas.

Sin embargo, se esgrimen deficiencias en la gestión pública municipal, desde la mala atención de los empleados de "Rentas", la desactualización de los sistemas informáticos hasta los problemas de calidad. Pero dicho esto, es importante comprender que las soluciones deben buscarse dentro de la misma administración.

Con los servicios de un contratista externo que "colabora" con las tareas propias del Estado, no solo se desdibuja la función propia del organismo, no lo complementa ni mejora, sino que le quita su especificidad: el control y la recaudación fiscal.

Resulta plausible todo intento del Estado destinado a modernizarse con el objeto de enfrentar los nuevos desafíos que encierra la gestión de los asuntos públicos. En ese contexto la iniciativa privada puede coadyuvar a través del suministro de tecnología, insumos, conocimiento, etc.

Las herramientas de la modernización del Estado deben buscarse en las jornadas de actualización de la Asesoría General de Gobierno; en el asesoramiento tributario del Ministerio de Economía; en la asistencia continua de la Agencia de Recaudación de la Provincia de Buenos Aires, quien, sin ir más lejos, desarrolló un programa destinado exclusivamente a la modernización municipal, brindando capacitaciones, fiscalizaciones, jornadas de recaudación, herramientas tecnológicas y geoespaciales de última generación.

Las herramientas gratuitas para hacer frente a estas concesiones municipales existen y pretenden dar batalla a las transacciones de los gobiernos municipales con el objeto de poner a resguardo las garantías constitucionales de los contribuyentes y el destino de la recaudación.

*Abogada UNLP - Especialista en Derecho Tributario UBA 